\title{
Differential life history responses of two Idotea species (Crustacea: Isopoda) to food limitation
}

\author{
Lars Gutow $^{1, *}$, Sonja Leidenberger ${ }^{2}$, Karin Boos ${ }^{2}$, Heinz-Dieter Franke ${ }^{2}$ \\ ${ }^{1}$ Alfred Wegener Institute for Polar and Marine Research, PO Box 120161, 27515 Bremerhaven, Germany \\ ${ }^{2}$ Biologische Anstalt Helgoland, Foundation Alfred Wegener Institute for Polar and Marine Research, Marine Station, \\ PO Box 180, 27483 Helgoland, Germany
}

\begin{abstract}
Organisms have to allocate assimilated energy appropriately among different life history processes in a way that maximizes individual fitness. Energy allocation schemes are shaped by the patterns of food availability that organisms experience in their environment. Therefore, species that have to cope with frequent and unpredictable food limitation are likely to exhibit adaptive life history responses that allow for persistence under adverse conditions and optimal use of temporarily available resources. We compared life history responses of 2 idoteid isopod species with contrasting life styles to different degrees of temporary food deprivation. The coastally distributed Idotea baltica (Pallas) usually has unlimited access to food in benthic macroalgal belts. The oceanic I. metallica Bosc inhabits objects floating at the sea surface and frequently experiences food limitation in oligotrophic open oceans. I. baltica was severely affected when food was temporarily limited, as indicated by a statistically significantly decreased population growth rate $(\lambda)$. I. metallica was less affected by temporary starvation. When food was limited, energy was allocated in $I$. metallica from development and reproduction to survival, enabling the isopods to outlast periods of unfavourable food conditions. In this species, a reduced $\lambda$ reflected slower gene propagation rather than a reduced fitness. A high lipid content allows I. metallica to outlast periods of starvation. Freshly hatched I. metallica have higher starvation resistance than juvenile $I$. baltica, making the demographically important juvenile stage less vulnerable to unpredictable food availability. The plastic responses of $I$. metallica to variable food levels represent efficient adaptations to life under conditions of low and unpredictable food availability and provide insight into the nutritional conditions with which organisms have to cope during extended rafting voyages at the surface of oligotrophic oceans.
\end{abstract}

KEY WORDS: Energetic trade-off $\cdot$ Population growth rate $\cdot$ Starvation resistance $\cdot$ Rafting $\cdot$ Internal reserves Resale or republication not permitted without written consent of the publisher

\section{INTRODUCTION}

In natural environments organisms often have to cope with limited resources, particularly food. Resource limitation exerts strong selective pressure on organisms resulting in evolutionary adaptations (Stelzer 2001). Longer periods of seasonal shortage and unavailability of resources are relatively predictable. Their persistent re-occurrence over evolutionary time scales has promoted the development of seasonal survival strategies such as dormancy and hibernation. In aquatic environments seasonal phytoplankton blooms provide periodical food pulses. This has resulted in the evolution of phenological patterns in consumers such as the appearance of particular ontogenetic stages during annual phases of enhanced food availability (e.g. Gislason et al. 2000, Gyllstroem \& Hansson 2004). Phenology is, however, of minor efficiency as a strategy for persistence in species living in non-equilibrium environments where incidental short term variations in food availability are unpredictable in time and space. Under such conditions animals require high starvation resistance and the potential for using food efficiently whenever it is temporarily available. Starvation resistance reflects the ability of an organism to store energy and to control 
its allocation during extended periods of resource limitation (Kirk 1997).

While an obligatory part of assimilated energy is invested in basic metabolic processes required for survival, surplus energy must be partitioned among diverse competing processes. These include somatic growth, reproduction and storage (Stelzer 2001). It is likely that the energy allocation scheme of a species in a particular environment has been shaped by natural selection in a way that maximises individual fitness (Sibly \& Calow 1986).

Experimental investigations on the effects of resource limitation on animals have been conducted at the individual level by applying indices of body condition such as lipid storage indices (Tessier \& Goulden 1982), RNA:DNA ratio (Melzner et al. 2005) or gonadal somatic indices (Hughes et al. 2005). Alternative and more comprehensive approaches work at the population level by assessing the effect of food limitation on a species' population growth rate $\left(\lambda_{i}\right.$ or $\left.r=\ln \lambda\right)$ (e.g. Merriman \& Kirk 2000). This is a commonly used measure of fitness as it describes how successfully a particular gene pool will propagate itself in future generations (Caswell 2001). Demographic approaches have been applied extensively on small planktonic rotifers in order to reveal adaptations to resource limitation (e.g. Merriman \& Kirk 2000, Stelzer 2001). Small herbivorous rotifers usually have short lifetime expectancies and high $\lambda$, providing significant population responses even in short term experiments (Merriman \& Kirk 2000). Experimental investigations on demographic responses of larger macro-invertebrate species with longer life spans are, however, usually time consuming and require higher logistic effort.

In the present study, we compared the life history responses of 2 idoteid isopod species to different temporal patterns of food deprivation. Despite their close relationship, the 2 congeners Idotea baltica (Pallas) and I. metallica Bosc exhibit fundamentally different life styles. I. baltica lives benthically in shallow coastal waters. Additionally, the species is encountered on macroalgae floating at the sea surface (Vandendriessche et al. 2006). This is, however, a temporary event in the life cycle of $I$. baltica and mainly restricted to coastal waters. In its typical subtidal to intertidal habitat, dense canopies of benthic macroalgae such as Fucus vesiculosus provide an apparently unlimited food resource. The fact that food is always available in excess to I. baltica is reflected in the species' wasteful feeding habits with high ingestion rates and inefficient assimilation of ingested food items (Gutow et al. 2006).

In contrast to Idotea baltica, I. metallica lives exclusively on floating objects (Thiel \& Gutow 2005b). The species is mainly associated with abiotic flotsam such as tar balls or plastic debris (Wong et al. 1974, Aliani \&
Molcard 2003). Because of their high persistence in the marine environment such abiotic items can serve as vehicles carrying associated organisms over very large distances along major oceanic surface currents (Thiel \& Gutow 2005a). Because of the generally low productivity of the oligotrophic open ocean (Longhurst et al. 1995), the patchy distribution of planktonic food (Steele 1976) and the scarce autochthonous food resources of a small abiotic raft, macrophagous species such as $I$. metallica are confronted with extended periods of starvation and only occasional and unpredictable food encounter during oceanic voyages. Consequently, as an obligate rafter, I. metallica has evolved an economic life style with low activity, efficient assimilation of ingested food items and accumulation of internal storage products (i.e. lipids; Gutow et al. 2006). The more economic use of available food resources by I. metallica indicates that this species may be better adapted to life in non-equilibrium environments than I. baltica. We, thus, hypothesise that I. metallica is less affected by resource limitation than I. baltica.

We analysed life history responses of both species to different degrees of temporal food deprivation in order to identify adaptive strategies of energy allocation in marine isopods. $\lambda$ resulting from plastic responses of life history parameters to food limitation were compared in order to reveal the relative adaptive efficiency of the observed energy allocation schemes. $\lambda$ is often particularly sensitive to variations in juvenile survival probabilities (Stearns 1992, Prevedelli \& Simonini 2001). An efficient strategy for persistence under variable resource availability would, thus, be selection for juveniles with high starvation resistance. We, therefore, focused on the starvation resistance of freshly hatched juveniles of Idotea baltica and I. metallica as well as on their potential for re-stocking internal reserves quickly from occasional food pulses as adaptations to life in environments of temporarily limited food supply. As lipids belong to the most important internal storage products in marine crustaceans (Hagen \& Auel 2001, Lee et al. 2006) we measured total lipid contents of male $I$. baltica and I. metallica and their quantitative changes during extended periods of starvation.

\section{MATERIALS AND METHODS}

Demographic consequences of food limitation. Individuals of the 2 isopod species Idotea baltica and I. metallica used in the present experiments were taken from mass cultures that were occasionally supplemented with individuals collected off the island of Helgoland, German Bight (North Sea). Food was permanently available in excess in the cultures. 
The isopods were kept individually in glass cups (diameter $6 \mathrm{~cm}$ ) with $50 \mathrm{ml}$ of seawater each from the day of hatching until death. The body length of adult males and females is about 17 and $28 \mathrm{~mm}$, respectively, for Idotea baltica and 16 and $22 \mathrm{~mm}$, respectively, for I. metallica (Gutow 2003a). Each day the sand/gravel-filtered seawater medium was changed. Each cup was supplied with a small piece of gauze (1 to $2 \mathrm{~cm}^{2}$ ) which served as a substratum to which the isopods could cling. The experiments were conducted at a constant temperature of $16^{\circ} \mathrm{C}$ and a daily light: dark cycle of 16:8 h light:dark (LD).

Throughout their lifetime, the isopods were exposed to 1 out of 4 quantitatively different feeding regimes which represented a gradient of temporal food availability: (1) at 100\% temporal food availability (hereafter referred to as Ba100 for Idotea baltica and Me100 for I. metallica) food was permanently available; (2) at $50 \%$ temporal food availability (Ba50 and Me50) $1 \mathrm{~d}$ of feeding alternated with $1 \mathrm{~d}$ of starvation; (3) at 33\% temporal food availability (Ba33 and Me33) $1 \mathrm{~d}$ of feeding alternated with $2 \mathrm{~d}$ of starvation; (4) at $25 \%$ temporal food availability (Ba25 and Me25) $1 \mathrm{~d}$ of feeding alternated with $3 \mathrm{~d}$ of starvation.

As long as food was offered, it was available in excess. The diet consisted of both fragments of the brown alga Fucus vesiculosus and freshly hatched Artemia sp. nauplii. Preceding experiments had revealed that this combination provides optimal food for both species.

Whenever a female was about to moult, a male was added for $24 \mathrm{~h}$ for mating. The isopods were monitored daily for life history traits such as age at sexual maturity, reproductive output and mortality. Sexual maturity in female Idotea sp. is reached with the formation of a complete marsupium.

In order to avoid effects of seasonality on the food requirements of the isopods, all treatments were started in summer (July and August). Each treatment was run in triplicate. Each replicate consisted of 17 to 24 individually reared isopods.

Demographic analysis. The demographic analysis was performed on females only. Sex ratios determined from the mature isopods of each replicate were never statistically significantly unequal $\left(\chi^{2}\right.$-test, p always $>0.05)$. As early juveniles cannot be sexed by external characteristics, sex-specific juvenile mortality was undeterminable. For simplification, an equal sex ratio was assumed for each experimental population. Each juvenile was valued as 0.5 individuals for the calculation of the survival probabilities of early juvenile ageclasses.

Data on weekly age-specific survival probability $(l[x])$ and fertility $(m[x])$ (female juveniles female ${ }^{-1}$ $\mathrm{wk}^{-1}$ ) provided life-tables that served to calculate $\lambda$ for each treatment from an age-structured matrix population model (Leslie matrix) with a projection interval of 1 wk. Matrix entries $P_{i}$ (survival probabilities) and $F_{i}$ (fertilities) were calculated using the birth-flow formulas developed by Caswell (2001: his Eqs. 2.24, $2.34 \& 2.35)$. $\lambda$ was obtained as the dominant eigenvalue of each matrix. Furthermore, net reproductive rate $R_{0}=\Sigma l(x) m(x)$ (i.e. the expected number of offspring by which a newborn individual will be replaced by the end of its life) and generation time $T=\ln R_{0} / \ln \lambda$ (wk) were calculated.

Decomposition analysis of treatment effects on $\lambda$. The high resolution (transition interval of $1 \mathrm{wk}$ ) of the matrix population model allows maximum use of the demographic information provided by the observed life history traits. Age at maturity, however, which is known to have a significant effect on $\lambda$ (Levin et al. 1996, Rochet 2000), is not explicitly taken into account in the matrix population model. Therefore, the effect of each treatment on $\lambda$ was decomposed by applying a simplified 2-stage model, with the 2 stages being classified as 'Juveniles' and 'Adults' (Levin et al. 1996). This model allows for decomposing not only the contribution of treatment-specific differences in stagespecific survival probabilities and mean fertilities to differences in $\lambda$, but also the contribution of differences in the age at maturity.

In the 2-stage model, juveniles develop with a survival probability $P_{J}$ in $\alpha$ time units (wk) to maturity. The transition to the adult stage was indicated by the first age-class in the life-table with non-zero fertility at time unit $\alpha+1$. $P_{J}$ was calculated as:

$$
P_{J}=\sigma_{1}^{\alpha}
$$

where $\sigma_{1}$ is the juvenile survival probability per unit time calculated as mean survival probability from all juvenile $P_{i}$ values. Adult survival probability $\sigma_{2}$ and ageindependent fertility $\bar{F}$ were calculated as weighted means of the adult $P_{i}$ and $F_{i}$ values. Each value was weighted according to the contribution of the corresponding age-class to the stable age distribution of the population which was obtained as the right eigenvector of the corresponding population matrix. The accuracy of the model was controlled by comparing $\lambda$ derived iteratively from the 2 -stage model using the following characteristic equation (Levin et al. 1996):

$$
\lambda^{\alpha+1}-\sigma_{2} \lambda^{\alpha}-P_{J} \bar{F}=0
$$

with $\lambda$ obtained from the corresponding population matrix. The contributions of treatment effects on $\sigma_{1}, \sigma_{2}$, $\bar{F}$, and $\alpha$ to the observed variations in $\lambda$ were determined by combining the differences $(\Delta x)$ between treatment $(t)$ and control $(c)$ values with the sensitivities of $\lambda$ to changes in the respective parameter $(\delta \lambda / \delta \mathrm{x})$ as shown in the following equation: 


$$
\lambda(c) \approx \lambda(t)+\frac{\delta \lambda}{\delta \sigma_{1}} \Delta \sigma_{1}+\frac{\delta \lambda}{\delta \sigma_{2}} \Delta \sigma_{2}+\frac{\delta \lambda}{\delta \alpha} \Delta \alpha+\frac{\delta \lambda}{\delta \bar{F}} \Delta \bar{F}
$$

As control we defined the treatments of permanent food availability (Ba100 and Me100) to which treatments of temporal food limitation were related. Sensitivities were calculated using Eqs. (12) to (15) from Levin et al. (1996) and evaluated as the mean of the 2 parameter sets.

Starvation capacity of juveniles: point-of-no-return (PNR) and point-of-reserve saturation (PRS). The experiments were conducted on freshly hatched juveniles of Idotea metallica and I. baltica. The isopods were kept individually in glass cups (diameter $4 \mathrm{~cm}$, volume $7 \mathrm{ml}$ ) with a small piece of gauze $\left(0.25 \mathrm{~cm}^{2}\right)$ at a constant temperature of $16^{\circ} \mathrm{C}$ and $16: 8 \mathrm{~h} \mathrm{~L}: \mathrm{D}$. The sand/gravel-filtered seawater was changed daily. PNR was determined by exposing the isopods to different initial starvation periods followed by continuous feeding. PRS was determined by feeding them for different periods before food was permanently withheld. Food consisted of freshly hatched Artemia sp. nauplii. The genus Idotea is considered omnivorous (Naylor 1955), but previous experiments have shown that juvenile development of the species in the present study (I. baltica and I. metallica) is impaired more seriously by a lack of animal food than by missing plant food, indicating that early juvenile nourishment is mainly based on animal food. Thus, Artemia sp. nauplii provide a suitable food for experiments on early juvenile starvation capacities. The isopods were monitored daily for mortality and moulting. For all treatments, 3 replicates were run with 20 individuals each.

The PNR concept was established as the threshold at which larvae are unable to recover from an initial starvation period and die before metamorphosis even when subsequently fed (Blaxter \& Hempel 1963). From the PRS onward, individuals are capable of completing larval development without any further feeding, at the cost of reserves accumulated during an initial feeding period (Anger \& Dawirs 1981). The metamorphosis of a larva represents a natural and ontogenetically relevant final point for experimental investigations on larval food requirements. Directly developing peracarid crustaceans, however, do not exhibit any obvious ontogenetic shift defining a final point for corresponding investigations on freshly hatched juveniles. Therefore, as the final point of the experiment, we chose the maximum number of moultings (+ 1) which the isopods could complete without any feeding. As this maximum number was 2 in both species, a treatment was declared finished when the isopods either had died or else had successfully completed the third moulting. When Artemia sp. nauplii were offered in excess in a preceding experiment the third moulting was completed by Idotea baltica after $18.7 \pm 1.1 \mathrm{~d}$ and by $I$. metallica after $18.1 \pm 1.6 \mathrm{~d}$. The difference of $0.6 \mathrm{~d}$ is less than the temporal resolution of the experiments (i.e. $1 \mathrm{~d}$ ) and thus allows direct comparison of starvation resistance by this method.

Survivorship $(Y)$ as a function of initial starvation period (PNR) or initial feeding period (PRS) was analysed by the following 'sigmoid dose-response' regression model:

$$
Y=M_{0}+\frac{M_{\mathrm{A}}-M_{0}}{1+10^{\left(\log P_{50}-t\right)}}
$$

Lethal starvation periods $P_{50}$ were determined as $\mathrm{PNR}_{50}$ and $\mathrm{PRS}_{50} . M_{0}$ denotes mortality without starvation. $M_{\mathrm{A}}$ is described by the asymptote to which mortality approaches with increasing initial starvation period or decreasing initial feeding period. The duration of starvation (PNR) and feeding (PRS) periods is expressed as $t(\mathrm{~d})$.

Quantitative lipid analysis. In order to avoid variations by different reproductive states, total lipid content was measured in adult males. Males were easily distinguished from females due to marked sexual dimorphism with respect to body size and shape. Individuals of Idotea metallica and I. baltica were taken from mass cultures where food was permanently available in excess. The isopods were kept individually in glass cups (diameter $6 \mathrm{~cm}$, volume $50 \mathrm{ml}$ ) at $16^{\circ} \mathrm{C}$ and 16:8 h L:D. The sand/gravel-filtered seawater was changed daily. After starvation periods of 0, 3, 6, 9 and $12 \mathrm{~d}, 6$ to 10 isopods each were deep-frozen at $-80^{\circ} \mathrm{C}$ for further analysis. The total lipid content of individuals was determined with the sulphophosphovanillin method after Zöllner \& Kirsch (1962) using a commercial test kit (Merck, Merckotest 3321). The procedure was modified after Saborowski \& Buchholz (1996) to be performed on microplates. The dry weight (DW) of lyophilised (Finn-Aqua Lyovac GT2E) individuals was determined with a precision of $0.01 \mathrm{mg}$ (Sartorius MC1 RC $210 \mathrm{~S}$ balance). Isopods were homogenized in $2 \mathrm{ml}$ of aqua dem. (demineralised water) by an Ultraturrax and subsequent sonication (Branson Sonifier Cell Disruptor B15). Lipids were extracted from $40 \mu \mathrm{l}$ subsamples vortexed for $50 \mathrm{~min}$ at $25^{\circ} \mathrm{C}$ in $1.5 \mathrm{ml}$ chlorophorm:methanol (2+1). After 15 min of centrifugation at $4^{\circ} \mathrm{C}$ and $15000 \times g$, supernatants of $1.3 \mathrm{ml}$ were transferred to fresh cups. The organic solvent was evaporated at $45^{\circ} \mathrm{C}$ within $1 \mathrm{~h}$ (Eppendorf concentrator 5301). The remaining lipids were dissolved in $500 \mu \mathrm{l}$ of sulphuric acid and boiled for at least $10 \mathrm{~min}$. Standards of cholesterol ( 0 to $150 \mu \mathrm{g}$ ) were treated in the same way. After cooling, samples of $20 \mu \mathrm{l}$ were transferred in triplicate onto each of 2 microplates. Samples of 1 microplate that served as blank received $350 \mu \mathrm{l}$ of phosphoric acid. Samples of the other plate received $350 \mu \mathrm{l}$ of sulphuric acid/vanillin. 

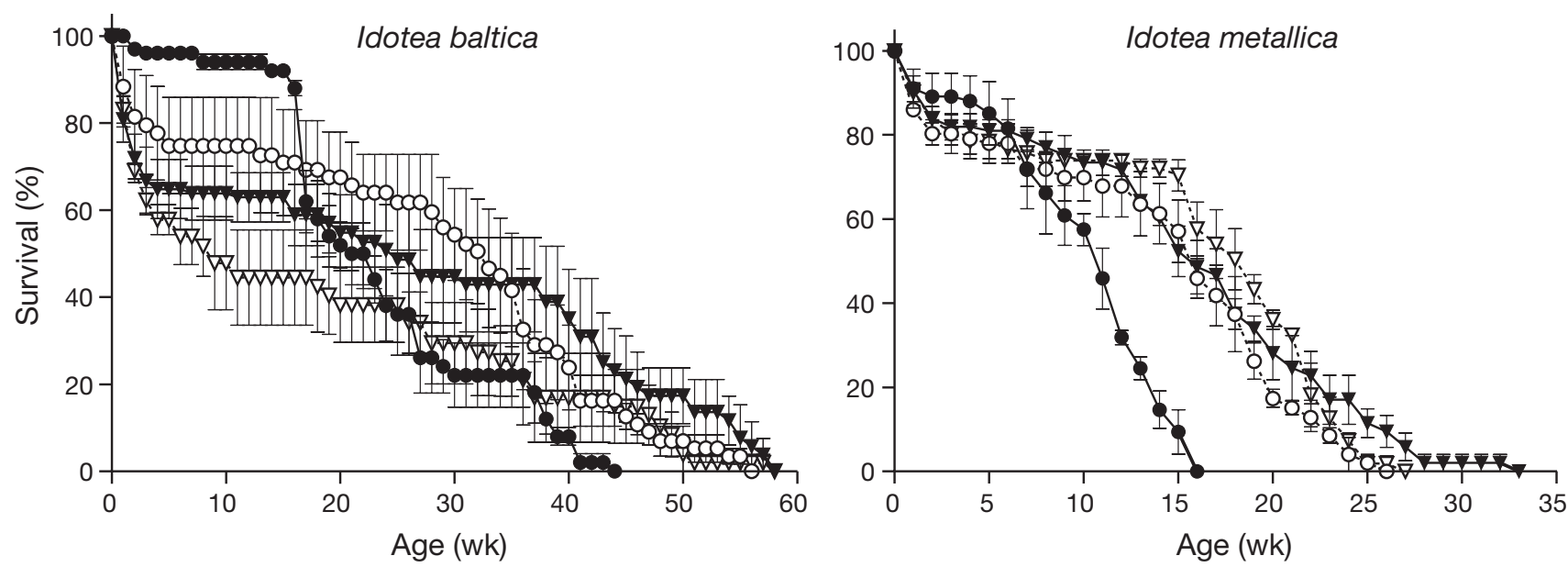

Fig. 1. Idotea baltica and I. metallica. Mean $\pm \mathrm{SE}(\mathrm{N}=3)$ survival curves of experimental populations of coastal $I$. baltica and oceanic I. metallica under different quantitative feeding regimes (\% temporal food availability): (O) $100 \%,(0) 50 \%,(\boldsymbol{\nabla}) 33 \%,(\nabla) 25 \%$

After $40 \mathrm{~min}$, both microplates were read at $530 \mathrm{~nm}$ (Dynatech, MR 7000). The sample plate was corrected for blank values.

\section{RESULTS}

\section{Demographic consequences of food limitation}

In female Idotea baltica, the mortality rate followed the same general pattern independent of feeding regime (Fig. 1). An initial juvenile mortality was followed by a fairly constant mortality rate in adults until the population became extinct. Juvenile survivorship was clearly affected by food limitation: the longer the intermittent periods of starvation, the higher the mortality. While juvenile mortality was only about $5 \%$ at Ba100, about $55 \%$ of the isopods died during juvenile development at $\mathrm{Ba} 25$. The age at $V_{50}$ increased from
Ba100 through Ba50 towards Ba33, but then dropped to the lowest value at Ba25. However, an ANOVA revealed no statistically significant differences between the $V_{50}$ values of the different treatments $(\mathrm{p}=0.532$; Table 1$)$.

In female Idotea metallica, mortality followed the same pattern as in female I. baltica (Fig. 1). However, in contrast to $I$. baltica, juvenile survival of $I$. metallica was not severely affected by food limitation. Under all feeding regimes, 10 to $20 \%$ of the individuals died during juvenile development. Surprisingly, the population with permanently available food reached $V_{50}$ very early in Week 11 (Table 1). The degree of food limitation, however, had no effect on the mortality rate of female I. metallica. In all treatments with intermittent starvation periods, $V_{50}$ was reached between Weeks 16 and 18.

The pattern of temporal food availability had a statistically significant influence on the developmental rate

Table 1. Idotea baltica and I. metallica. Life history traits under different feeding regimes. Different superscripts denote statistically significant differences between conspecifics from different treatments. $V_{50}: 50 \%$ extinction

\begin{tabular}{|c|c|c|c|c|}
\hline \multirow[t]{2}{*}{ Parameter } & \multicolumn{4}{|c|}{ Temporal food availability (\%) } \\
\hline & 100 & 50 & 33 & 25 \\
\hline \multicolumn{5}{|l|}{ Idotea baltica } \\
\hline$V_{50}(\mathrm{wk})$ & $21.9 \pm 4.7^{\mathrm{a}}$ & $27.8 \pm 13.3^{\mathrm{a}}$ & $28.0 \pm 13.8^{a}$ & $16.0 \pm 10.1^{\mathrm{a}}$ \\
\hline Mean age at sexual maturity (wk) & $8.0 \pm 1.0^{\mathrm{a}}$ & $11.4 \pm 0.9^{\mathrm{b}}$ & $15.2 \pm 0.8^{\mathrm{c}}$ & $20.4 \pm 1.5^{\mathrm{c}}$ \\
\hline $\begin{array}{l}\text { Mean lifetime reproductive success } \\
\text { (no. of offspring female } \text { fe }^{-1} \text { ) }\end{array}$ & $380.3 \pm 253.6^{\mathrm{a}}$ & $377.4 \pm 233.6^{\mathrm{a}}$ & $186.4 \pm 123.2^{\mathrm{b}}$ & $94.4 \pm 72.2^{\mathrm{b}}$ \\
\hline \multicolumn{5}{|l|}{ Idotea metallica } \\
\hline$V_{50}(\mathrm{wk})$ & $10.6 \pm 0.6^{\mathrm{a}}$ & $15.5 \pm 2.8^{\mathrm{b}}$ & $16.1 \pm 1.5^{\mathrm{b}}$ & $17.1 \pm 1.5^{\mathrm{b}}$ \\
\hline Mean age at sexual maturity (wk) & $6.4 \pm 0.7^{\mathrm{a}}$ & $8.5 \pm 0.7^{b}$ & $11.1 \pm 1.0^{\mathrm{c}}$ & $12.8 \pm 0.7^{\mathrm{d}}$ \\
\hline $\begin{array}{l}\text { Mean lifetime reproductive success } \\
\text { (no. of offspring female }{ }^{-1} \text { ) }\end{array}$ & $51.1 \pm 50.7^{a}$ & $70.9 \pm 58.2^{\mathrm{a}}$ & $47.5 \pm 38.2^{\mathrm{a}}$ & $18.6 \pm 19.4^{\mathrm{b}}$ \\
\hline
\end{tabular}


of female Idotea baltica (Kruskal-Wallis test, p < 0.0001, Fig. 2). Sexual maturity was reached earliest at Ba100. No differences in the developmental rates (i.e. mean age at sexual maturity) were detected between Ba33 and Ba25 (Dunn's multiple comparison test, p > 0.05, Table 1). As a consequence of delayed development, reproduction began later when food was not permanently available (Fig. 3). Once started, reproductive activity of the isopods continued until death in all treatments. Lifetime reproductive success, calculated as the total number of offspring per female, was equal at Ba100 and Ba50 but decreased with further food limitation (ANOVA, p $<0.0001$; Table 1). It was significantly reduced by the factors 2 and 4 at Ba33 and Ba25, respectively.

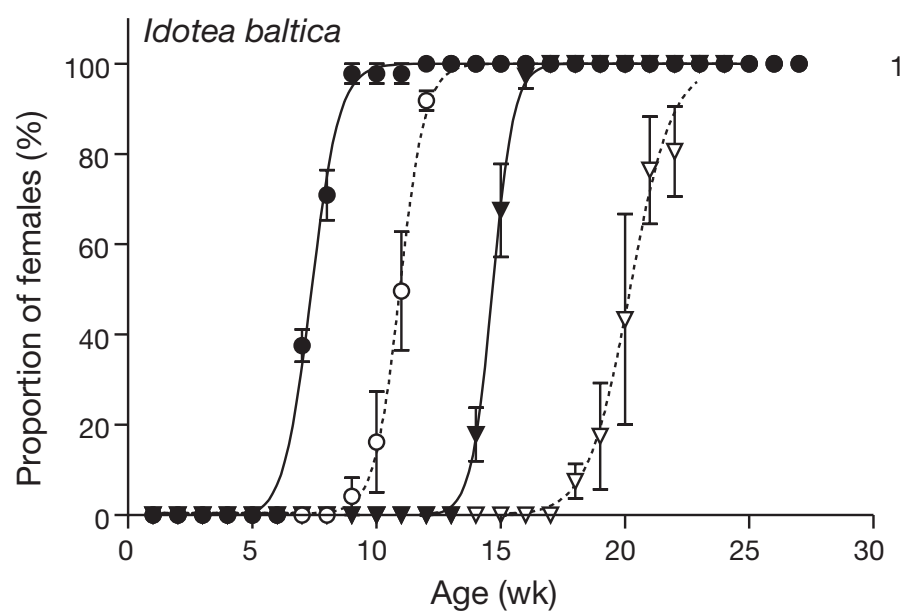

As in Idotea baltica, sexual maturity in I. metallica was reached earliest when food was permanently available (Fig. 2). Temporal food limitation statistically significantly reduced the rate of development (Kruskal-Wallis test, $\mathrm{p}<0.0001$ ). A reduction of the temporal food availability to $25 \%$ doubled the time required for sexual maturation from $6.4 \mathrm{wk}$ (Me100) to $12.8 \mathrm{wk}$ (Table 1).

Reproductive rates of Idotea metallica were highest in early adult stages (Fig. 3). Lifetime reproductive success increased from Me100 to Me50 and decreased only little at Me33 (Tukey's test, p > 0.05; Table 1). Only a reduction of the temporal food availability by $75 \%$ (Me25) significantly affected the mean fertility of the isopods.

Fig. 2. Idotea baltica and I. metallica. Mean $\pm \mathrm{SE}(\mathrm{N}=3)$ sexual maturation under different quantitative feeding regimes $(\%$ temporal food availability): (•) $100 \%,(0) 50 \%,(\nabla) 33 \%,(\nabla) 25 \%$
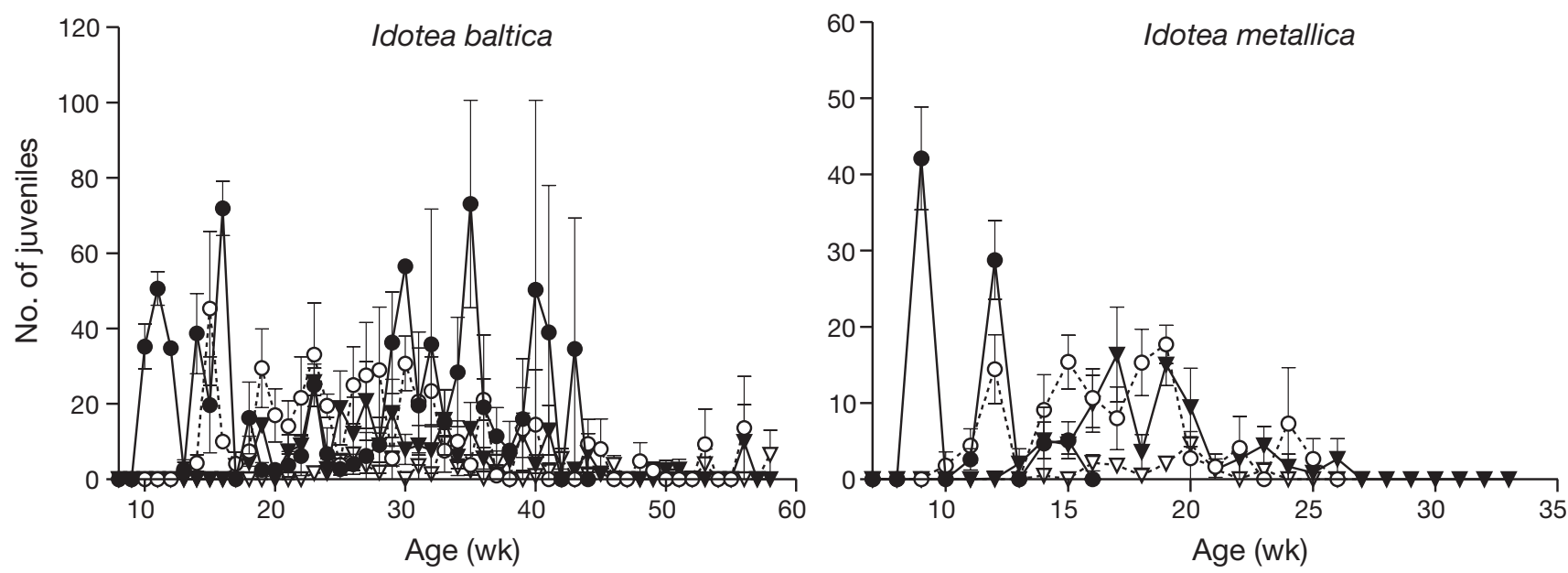

Fig. 3. Idotea baltica and I. metallica. Mean $\pm \mathrm{SE}(\mathrm{N}=3)$ age-specific reproductive output of females under different quantitative feeding regimes (\% temporal food availability): (৩) $100 \%$, (O) $50 \%,(\boldsymbol{\nabla}) 33 \%,(\nabla) 25 \%$ 


\section{Demographic analysis}

The dependency of $\lambda$ (calculated from the matrix population model) on the temporal food availability was described by the following Monod model (Tilman 1982) (Fig. 4):

$$
\lambda=\lambda_{\max } \times\left(\frac{m}{\left(K_{\mathrm{S}}+m\right)}\right)
$$

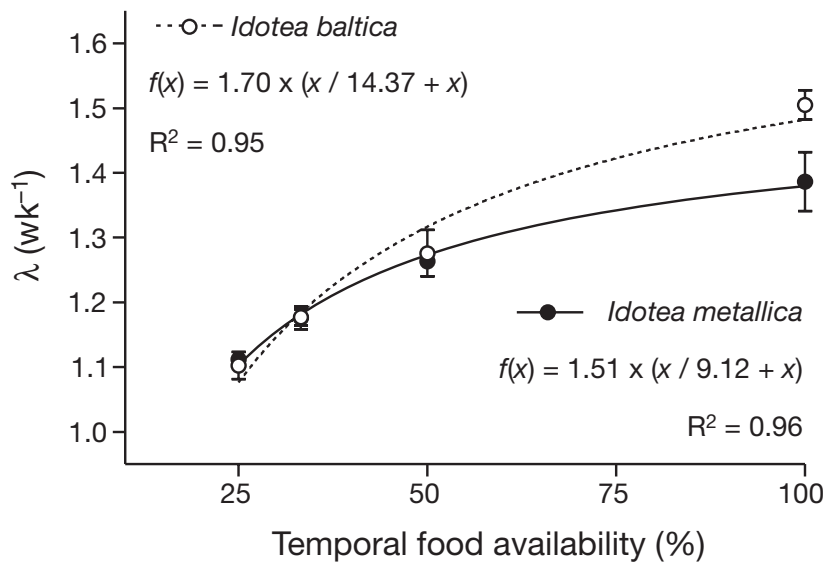

Fig. 4. Idotea baltica and I. metallica. Mean $\pm \mathrm{SD}(\mathrm{N}=3)$ population growth rates $(\lambda)$ under different feeding regimes analysed by Monod model where $\lambda_{\max }$ is maximum population growth rate, $m$ is concentration of the limiting resource, and $K_{\mathrm{S}}$ is the resource concentration for half saturation.

A 2-factorial ANOVA revealed that in both species the pattern of temporal food availability had a significant effect on $\lambda$ (Table 2). At permanent food availability $\lambda$ was higher in Idotea baltica than in I. metallica. However, $\lambda$ of $I$. baltica was more sensitive to food limitation. At 25 and $33 \%$ temporal food availability, $\lambda$ was slightly higher in $I$. metallica than in I. baltica. This was reflected in a statistically significant interaction of the 2 factors 'Food availability' and 'Species'. $\lambda$ was equal in both species at a calculated $32.3 \%$ temporal food availability, which was roughly achieved in the Ba33 and Me33 treatments. The temporal threshold resource concentration $R^{*}$ for population persistence (i.e. $\lambda=1$ ) was calculated from the Monod model for both species. Population persistence was achieved by I. baltica at $20.7 \%$ temporal food availability. Referring to the present experimental design ( $1 \mathrm{~d}$ periods of feeding alternating with starvation periods) this corresponds to starvation periods of $3.6 \mathrm{~d}$. I. metallica required a temporal food availability of only $18.0 \%$ for population persistence, corresponding to starvation periods of $4.1 \mathrm{~d}$.

As with $\lambda$, the net reproductive rate $\left(R_{0}\right)$ was more sensitive to food limitation in Idotea baltica than in I. metallica, which is again reflected in a statistically significant interaction between the 2 main factors (Table 2). In I. baltica, $R_{0}$ was statistically significantly reduced in both Ba33 and Ba25. In I. metallica, however, it was only at Me25 that $R_{0}$ was markedly reduced.

In both species, generation time ( $T$ ) increased gradually with decreasing temporal food availability (Table 2). As $T$ directly depended on $\lambda$ and $R_{0}$, variations in $T$ were not compared statistically.

\section{Decomposition analysis of treatment effects on $\lambda$}

Values of $\lambda$ calculated from the 2stage model agreed very well with $\lambda$ calculated from the corresponding population matrix. Pairwise comparisons never revealed any statistically significant difference (Student's $t$-test, p always $>0.05$ ).

In Idotea baltica, age at maturity was statistically significantly affected by all degrees of food limitation (Table 3). 
Table 3. Idotea baltica and I. metallica. Parameterisation of 2-stage model and resulting population growth rates $(\lambda)$. Different superscripts denote statistically significant differences between conspecifics from different treatments. $\alpha=$ age at maturity; $\sigma_{1}=$ juvenile survival probability; $\sigma_{2}=$ adult survival probability; $\bar{F}=$ mean fertility

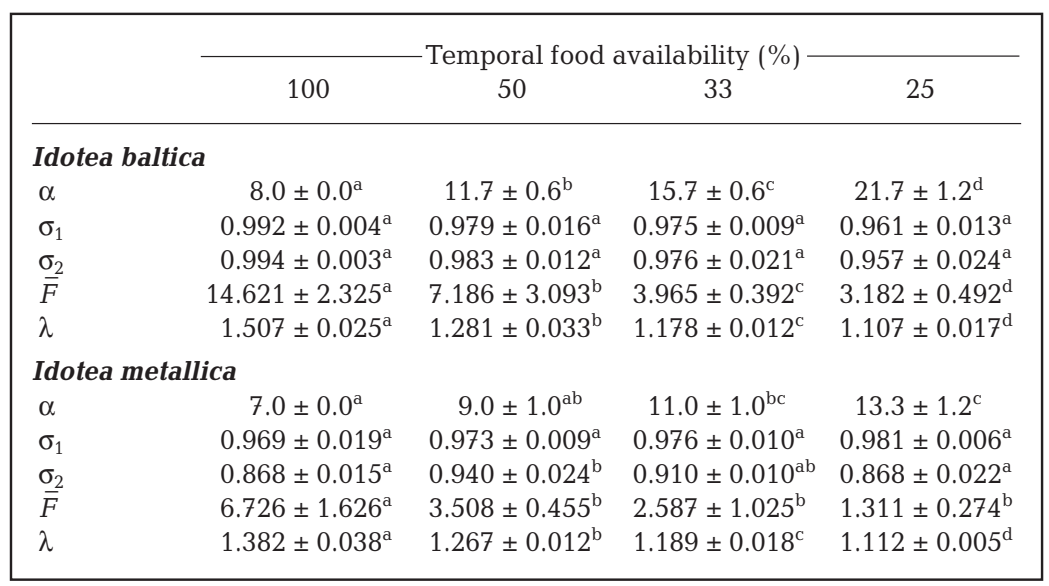

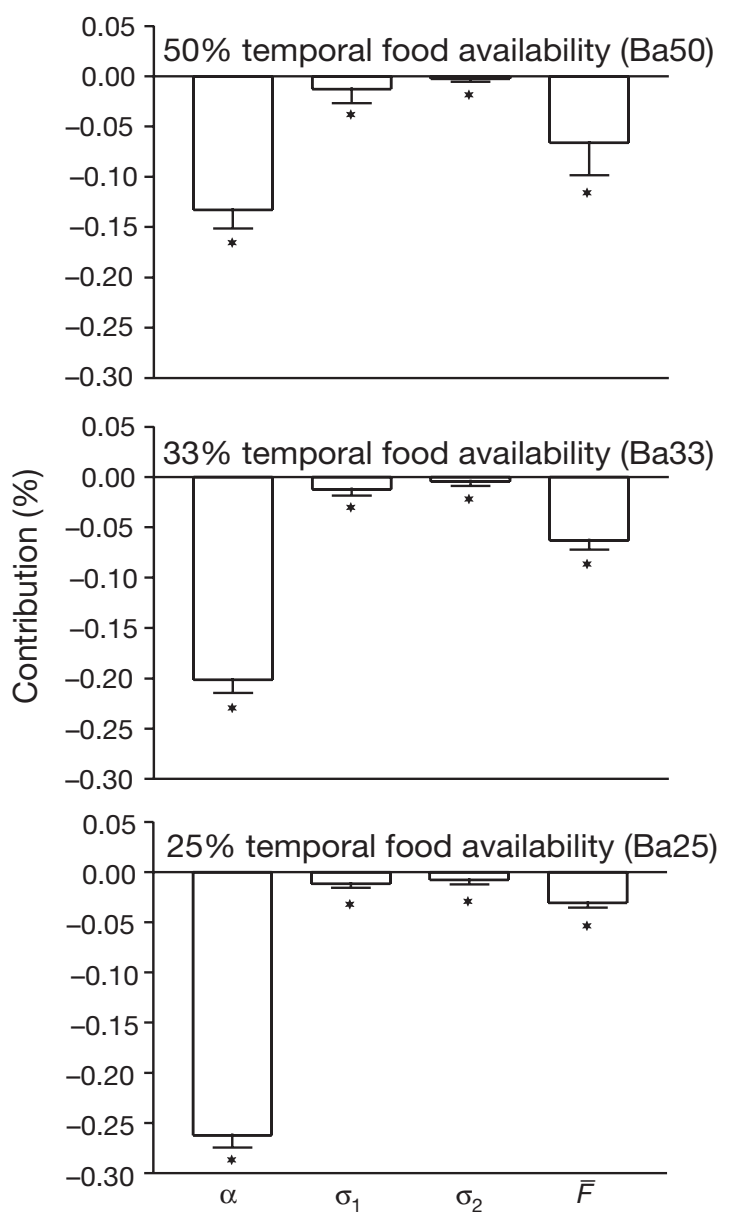

Fig. 5. Idotea baltica. Results (mean $\pm \mathrm{SD}$ ) of decomposition analysis of effects of food limitation on $\lambda$ relative to control (permanent food availability). ${ }^{*}$ Statistically significant negative contributions to variation in $\lambda_{;} \alpha=$ age at maturity; $\sigma_{1}=$ juvenile survival probability; $\sigma_{2}=$ adult survival probability;

$$
\bar{F}=\text { mean fertility }
$$

$\alpha$ increased from 8 wk for Ba100 to about $22 \mathrm{wk}$ for Ba25. Survival probabilities of both juveniles $\left(\sigma_{1}\right)$ and adults $\left(\sigma_{2}\right)$ as well as mean fertilities $(\bar{F})$ decreased continuously with decreasing temporal food availability. The differences in survival probabilities were, however, not statistically significant, while the fertility was markedly reduced when food was only temporarily available (Table 3 ). Fig. 5 shows the contributions of the differences in each life history parameter to the variation in $\lambda$ compared to the control (Ba100) caused by different degrees of temporal food limitation. Even though the lower survival probabilities contributed only little (always $<10 \%$ ) to a decrease in $\lambda$, the generally negative contribution was always statistically significant (1-sample $t$-test for deviation from 0 : $p$ always $<0.05$ ). $\lambda$ was mainly affected by the delayed maturation of the juveniles. The negative effect of this parameter increased with increasing duration of food deprivation. The effect of the reduced fertility on $\lambda$ decreased with increasing food limitation, yet remained statistically significant for all treatments of food limitation.

In Idotea metallica, juvenile survival probabilities were lowest when food was permanently available (Table 3). $\sigma_{1}$ increased with increasing food limitation (Table 3) and contributed positively to the value of $\lambda$, relative to the control, at 33 and $25 \%$ temporal food availability (Fig. 6). Survival probability of adult I. metallica was highest at $50 \%$ temporal food availability and decreased at 33 and $25 \%$ temporal food availability. At Me25 the positive contribution of $\sigma_{2}$ to $\lambda$ was no longer statistically significant, since adult survival probabilities were similar at Me100 and Me25.

Consequently, in Idotea metallica, $\lambda$ was only affected by reduced fertility and delayed maturity. The negative contribution of these parameters to $\lambda$ was statistically significant for all degrees of food limitation.

\section{Starvation capacity of juveniles: PNR and PRS}

Juvenile Idotea metallica survived initial starvation periods longer than I. baltica (Fig. 7 a). PNR $_{50}$ was $7.3 \pm$ $0.1 \mathrm{~d}$ for $I$. metallica, and $3.7 \pm 0.5 \mathrm{~d}$ for $I$. baltica. The difference was statistically significant (Student's $t$-test, $\mathrm{p}=0.001$ ). Furthermore, I. baltica required a longer initial feeding period for the completion of the third moult than I. metallica (Fig. $7 \mathrm{~b}$; for equation and correlation coefficients see Table 4 ). $\mathrm{PRS}_{50}$ was $11.4 \pm 0.7 \mathrm{~d}$ 
$50 \%$ temporal food availability (Me50)

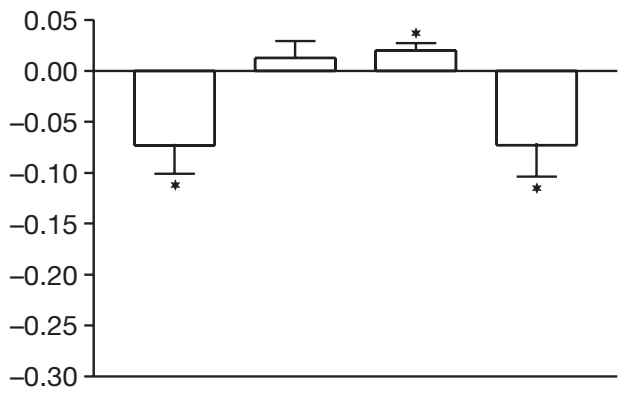

$33 \%$ temporal food availability (Me33)
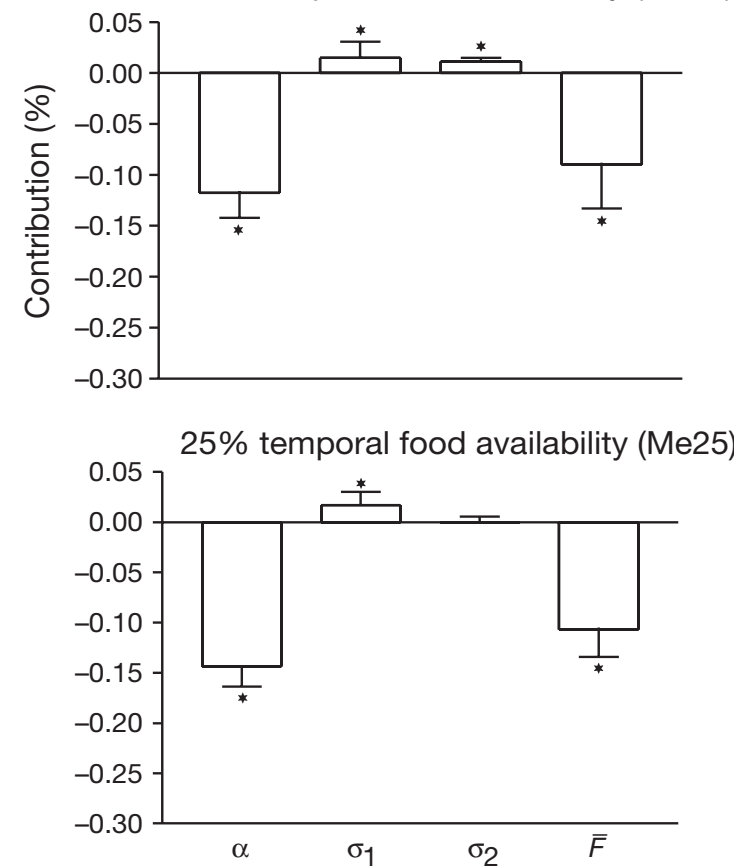

Fig. 6. Idotea metallica. Results (mean $\pm \mathrm{SD}$ ) of decomposition analysis of effects of food limitation on $\lambda$ relative to control (permanent food availability). ${ }^{*}$ Statistically significant positive or negative contributions to variation in $\lambda_{i} \alpha=$ age at maturity; $\sigma_{1}=$ juvenile survival probability; $\sigma_{2}=$ adult survival probability; $\bar{F}=$ mean fertility

for I. metallica, and $14.1 \pm 0.9 \mathrm{~d}$ for I. baltica (Student's t-test, $\mathrm{p}=0.013$ ).

\section{Quantitative lipid analysis}

A 2-factorial ANOVA revealed differences in the total lipid content between the 2 species $(p=0.001)$ (Fig. 8). The initial lipid content (i.e. without starvation) was statistically significantly higher in Idotea metallica than in I. baltica (Newman-Keuls multiple comparison test, $\mathrm{p}<0.05$ ). The lipid content also proved to be dependent on the duration of the starvation period
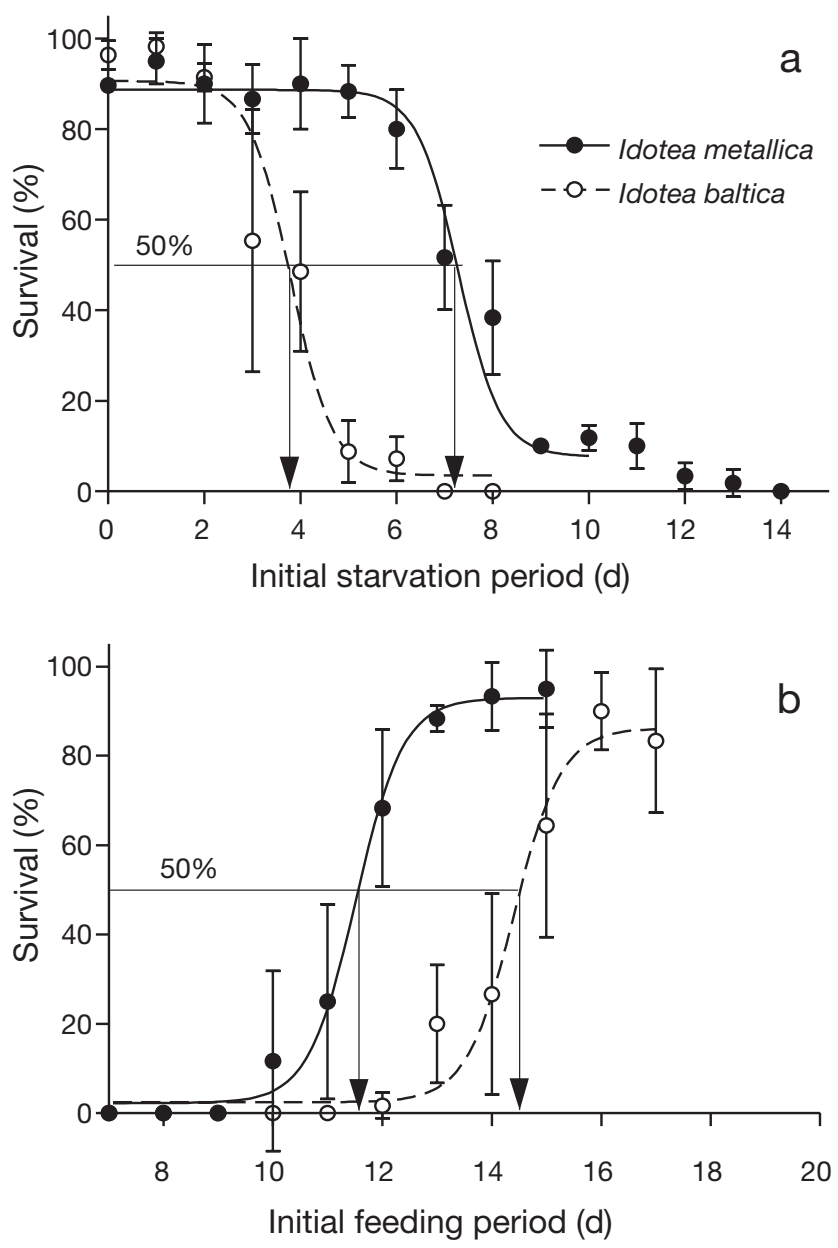

Fig. 7. Idotea baltica and I. metallica. Mean $\pm \mathrm{SD}(\mathrm{N}=3)$ percentage survival of freshly hatched isopods after different initial periods of (a) starvation and (b) feeding. Arrowheads indicate $\mathrm{PNR}_{50}$ and $\mathrm{PRS}_{50}$ values

Table 4. Idotea baltica and I. metallica. Specific equations and correlation coefficients $\left(\mathrm{R}^{2}\right)$ of sigmoid dose-response regression model describing survival of freshly hatched isopods in point-of-no-return (PNR) and point-of-reserve saturation (PRS) experiments

\begin{tabular}{|lcc|}
\hline Species & Equation & $\mathrm{R}^{2}$ \\
\hline PNR & $f(x)=90.61+\frac{3.51-90.61}{1+10^{(3.80-x)}}$ & 0.89 \\
Idotea baltica & $f(x)=88.65+\frac{7.68-88.65}{1+10^{(7.30-x)}}$ & 0.95 \\
Idotea metallica & $f(x)=2.46+\frac{86.19-2.46}{1+10^{(14.41-x)}}$ & 0.90 \\
Idotea baltica & $f(x)=2.27+\frac{92.94-2.27}{1+10^{(11.52-x)}}$ & 0.95 \\
Idotea metallica & $f(x)$ & \\
\hline
\end{tabular}


(2-factorial ANOVA, $p=0.002)$. As the lipid content of I. baltica was not affected by starvation (NewmanKeuls multiple comparison test, p always $>0.05$ ) this dependence was mainly due to a statistically significant decrease in the lipid content of I. metallica during the first $3 \mathrm{~d}$ of starvation (Newman-Keuls multiple comparison test, $\mathrm{p}<0.05)$. The interaction between the 2 factors 'Species' and 'Starvation period' was, however, statistically not significant $(\mathrm{p}=0.398)$. During further starvation, the lipid content of $I$. metallica remained constant (Newman-Keuls multiple comparison test, p always $>0.05)$.

\section{DISCUSSION}

Both Idotea baltica and I. metallica responded clearly to the experimental levels of temporal food deprivation. In both species $\lambda$ decreased when access to food was temporarily restricted. The response was stronger in I. baltica than in I. metallica. This result supports our initial hypothesis that I. metallica, which is frequently exposed to periods of low food availability in its natural epipelagic offshore environment, is better adapted to irregular food supply than I. baltica, which usually encounters food in permanent excess in extensive coastal macroalgal belts.

\section{Adaptive responses to food limitation}

Any degree of food limitation inevitably reduces the amount of surplus energy which is available to an organism for somatic processes such as development, growth and reproduction after the basic metabolic requirements for survival are met. Survival alone, how-

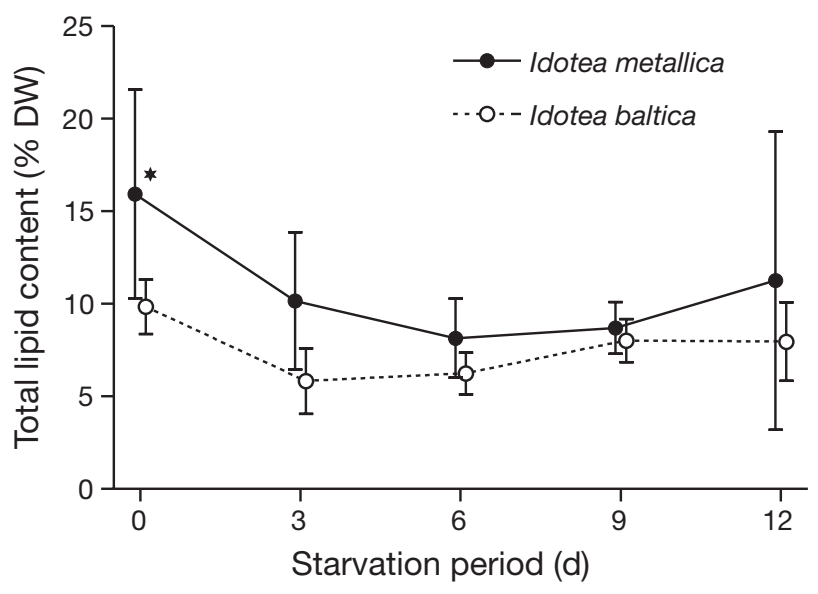

Fig. 8. Idotea baltica and I. metallica. Mean $\pm \mathrm{SD}(\mathrm{N}=6$ to 10$)$ total lipid content of males after different periods of starvation. ${ }^{*}$ Statistically significantly higher lipid content of unstarved male I. metallica. DW: dry weight ever, is evolutionary meaningless as long as it does not allow for propagation (Pianka 1981). Even under conditions of food limitation a certain amount of energy has to be allocated to reproduction at the expense of other processes. The accurate partitioning of energy among competing life history processes is, thus, decisive for the performance of a species when food is limited.

In Idotea baltica, maturation of juveniles was delayed when food was intermittently deprived. Juvenile survival $\left(\sigma_{1}\right)$ apparently profited from the energy saved in this way. $\sigma_{1}$ was not statistically significantly affected by moderate food limitation although it declined continuously when the duration of the starvation periods increased. Starvation also had little effect on adult survival $\left(\sigma_{2}\right)$, probably due to the allocation of energy away from fertility $(\bar{F})$ which was substantially reduced. Even though the variations in survival probability were statistically not significant in I. baltica, the high sensitivity of $\lambda$ to variations in survival probabilities resulted in a statistically significant contribution of reduced survival to the observed decrease in $\lambda$ under conditions of limited food availability.

According to Tuomi et al. (1988), female Idotea baltica adjust their offspring production to limited energy in order to avoid direct survival costs of reproduction. This 'restrained' reproductive strategy (sensu Calow \& Sibly 1983) was considered especially favourable for peracarid crustaceans because these animals develop directly within the mother's brood pouch and exhibit a continuous mode of reproduction. Mortality of ovigerous females would, thus, inevitably lead to the loss of entire broods. Ensuring the survival of females at the expense of brood size allows at least some degree of successful reproduction.

The factor with the strongest negative effect on $\lambda$ in starved Idotea baltica was delayed maturity $(\alpha)$. About 60 (Ba50) to $85 \%$ (Ba25) of the total variation in $\lambda$ relative to the control (Ba100) could be attributed to the late onset of reproduction. The resulting shortening of the reproductive adult stage together with the slightly reduced survival probability in starved $I$. baltica makes $\lambda$ less sensitive to variations in fertility. Consequently, the contribution of $\bar{F}$ to the decrease in $\lambda$ was lowest when food limitation was maximal (Ba25). This, in turn, indicates that even if reproduction was not, or only slightly, affected by starvation, this could not compensate for the delayed maturity and increased mortality. $\bar{F}$ was, however, heavily affected by starvation without any statistically significant benefit for development and survival. Possible energetic trade-offs between different somatic processes in I. baltica were, thus, insufficient to prevent severe restrictions in the isopods' fitness by starvation. The species has only minor capacity to compensate impairments in any of the considered life history parameters which are affected even by short peri- 
ods of starvation. The frequency and duration of episodes of extremely low resource quantity experienced by an organism are important selective factors for energy allocation schemes (Kirk 1997). Accordingly, our results indicate that $I$. baltica rarely faces periods of resource limitation in its natural environment and is, thus, only poorly adapted to food limitation.

In Idotea metallica, temporary starvation also resulted in delayed maturity. In contrast to $I$. baltica, however, the delay in sexual development coincided with better $\sigma_{1}$, indicating energy allocation from development to survival in juvenile $I$. metallica. The increase in $\sigma_{1}$ was statistically not significant yet consistent, resulting in statistically significant positive contributions to $\lambda$ in the treatments of strongest food limitation (Me33 and Me25).

In contrast to Idotea baltica, in I. metallica the negative effect of reduced fertility on $\lambda$ increased with increasing duration of the intermittent periods of starvation. The significant negative contribution of reduced fertility to $\lambda$ in starved $I$. metallica is indicative of the sensitivity of $\lambda$ to changes in $\bar{F}$. Higher survival probabilities relative to the control individuals increase the probability of reaching the adult stage and reproducing repeatedly during an extended life span. The generally negative effect of $\bar{F}$ on $\lambda$ in starved I. metallica obscures the fact that $R_{0}$ was statistically significantly affected only when food was unavailable for $75 \%$ of the time (Me25). At $50 \%$ temporal food availability, $R_{0}$ was even slightly higher than in the controls. $\bar{F}$ represents the age-independent weekly fertility that was set equal for all adult age classes in the applied population model. The total number of offspring was evenly distributed over the entire adult stage according to the stable age distribution, resulting in lower weekly fertility rates in starved individuals due to an extended adult stage. Therefore, the decrease in $\lambda$ at moderate degrees of temporal food deprivation (Me50 and Me33) reflects slower gene propagation in I. metallica, as also indicated by extended $T$, rather than a reduced probability of gene propagation (i.e. fitness). This strategy allows the isopods to better outlast periods of food limitation. Furthermore, it avoids the fast accumulation of conspecific consumers during adverse periods and, thus, limits intraspecific competition for already limited resources. This appears particularly important in species with limited opportunities for emigration from resourcedepleted habitat patches in heavily fragmented landscapes such as isolated floating rafts in the open ocean.

However, caution is required when the above conclusions are transferred to the field situation. The laboratory experiments ignored important natural intraand interspecific constraints such as cannibalism and predation. Even though the intrinsic survival probability was not affected by starvation, a delayed matura- tion increases the risk of dying through natural constraints such as competition or predation before successful reproduction has taken place (Bell 1984). Accordingly, some species mature earlier in life (Tollrian \& Dodson 1999, for cladocerans) or reduce the breeding interval (Dzikowski et al. 2004, for guppies) under predatory pressure. Animals rafting on floating objects are exposed to high predatory pressure from the atmosphere (i.e. sea birds) (Furness \& Todd 1984, Kirkman \& Kendrick 1997), predators in the water below them (e.g. fish) (Dooley 1972, Shaffer et al. 1995) and from co-occurring predators on the raft (Edgar 1987, Sano et al. 2003). Furthermore, cannibalism on juveniles is common among idoteids and increases when alternative food is scarce (Franke \& Janke 1998). Therefore, eruptive reproduction early in life probably is advantageous but obviously requires large amounts of energy, which was available to Idotea metallica only when food was not limited (Me100). Unlike I. baltica, which ensures survival of adult females by limiting reproduction, adult survival in $I$. metallica is reduced under surplus food conditions in favour of early reproduction. The latter species has, thus, the potential to adjust its reproduction to the degree of food availability by switching between a 'restrained' and a 'reckless' reproductive strategy (sensu Calow \& Sibly 1983).

Generally, Idotea metallica responded more flexibly to variations in food levels than I. baltica. While I. baltica was, at most, able to avert increased mortality by energy allocation from development and reproduction to survival, I. metallica even increased its survival probability with much less pronounced losses in development and fertility. Energetic trade-offs between survival and reproduction are common and have been reported from many different taxa including invertebrates and vertebrates (see Stearns 1992 for an extensive review). The potential to increase survival at the expense of reproduction under adverse conditions allows organisms to outlast periods of low food availability and is interpreted as an adaptation to frequent and unpredictable food scarcity (Kirk 1997). However, there is no uniform response to food limitation. The responses vary with life history characteristics and habitat-specific patterns of food availability (e.g. Stelzer 2001). Accordingly, further comparable studies on a wider variety of species from the 2 contrasting habitats considered herein are recommended.

\section{Internal reserves}

As an adaptation to low and unpredictable food levels male Idotea metallica use available food resources more economically than male $I$. baltica (Gutow et al. 2006) and possess more extensive internal resources 
(i.e. lipids). The lipid content of unstarved male I. metallica was exceptionally high and comparable to that of male isopods from polar latitudes that characteristically have to cope with food scarcity. The total lipid content of I. metallica of $16 \%$ DW is similar to the $17 \%$ DW lipid content of the antarctic isopod Serolis pagenstecheri (Clark 1984) and even twice as high as the values $(8 \%$ DW) measured in the arctic isopod Mesidotea entomon (Korczynski 1989).

In male Idotea metallica, the total lipid content decreased significantly during the first $3 \mathrm{~d}$ of starvation. In I. baltica, in contrast, the lipid content remained fairly constant over the entire starvation period, indicating that this species reverts to other internal reserves such as proteins as well. It remains unknown whether these results from adult males are transferable to females and juveniles. Since we measured the total lipid content of the isopods without characterising the lipid classes into storage lipids and structural lipids we cannot say whether the decrease in lipid content can actually be attributed to the degradation of storage lipids. The statistically significant reduction of the total lipid content in $I$. metallica during the first $3 \mathrm{~d}$ of starvation is, however, consistent with the pattern of reserve usage observed in other isopod species with limited access to food and might represent an adaptation to frequent food limitation. The freshwater isopod Asellus aquaticus, for example, exhausts its entire organic reserves quickly during temporary starvation (Hervant \& Renault 2002). In contrast, the subterranean Stenasellus virei, which has only sporadic access to food, uses internal storage products more slowly and stepwise: carbohydrates are metabolised first, followed by lipids, before the isopods finally draw on proteins (Hervant \& Renault 2002). Furthermore, $S$. virei is able to replenish its reserves quickly after starvation by optimal food usage.

Juvenile Idotea metallica were also able to replenish their reserves quickly during the initial feeding period of the PRS experiments, allowing them to survive and develop better during the subsequent starvation period. The feeding period required for successful development through the third moulting was about $3 \mathrm{~d}$ shorter in I. metallica than in I. baltica. Accordingly, freshly hatched I. metallica survived about $3 \mathrm{~d}$ longer without any food than juvenile I. baltica in the PNR experiments, indicating that new born I. metallica are already better equipped with storage products (i.e. maternal yolk). Similar results were obtained by Paschke et al. (2005), who found higher starvation resistance in early larvae of the North Sea shrimp Crangon crangon hatched in winter than in larvae hatched in summer. The larger winter larvae had a higher initial biomass than the summer larvae, allowing better survival during periods of low and unpre- dictable planktonic food availability in winter and early spring.

Under surplus food conditions, clutch size is on average 2.6 times larger in Idotea baltica than in I. metallica (L. Gutow pers. obs.). The cost of equipping the embryos of I. metallica with extensive storage products is obviously reduced fertility.

\section{Ecological implications}

Idotea metallica is an obligatory rafter that lives exclusively on objects floating at the sea surface and must be expected to be particularly adapted to this life style. The contrasting responses of I. baltica and I. metallica to food limitation shed some light on the poorly investigated nutritional conditions which rafting organisms experience during their epipelagic voyages. The offshore ocean surface is a low food habitat due to the generally low productivity of oligotrophic oceans (Longhurst et al. 1995). In contrast to planktonic species, however, rafters live in an often densely populated and diverse rafting community of plants and animals (Thiel \& Gutow 2005b) that potentially provides equally diverse food resources for macrophagous species. Nevertheless, I. metallica is well adapted to starvation. This indicates that organisms co-occurring on the raft probably do not represent the primary food resource for obligatory rafters. By qualitative lipid analysis, Turner \& Rooker (2006) revealed that the food web of the North Atlantic Sargassum community is mainly based on planktonic primary production instead of Sargassum spp. production, even though these large macroalgae provide huge amounts of biomass in the open ocean (Butler \& Stoner 1984, Niermann 1986). Obviously, autochthonous resources such as the algal rafts themselves or associated rafters are even more unreliable and unsustainable than the sparse plankton. Furthermore, consumption of the algal raft would inevitably lead to habitat destruction with fatal consequences for the associated organisms (Gutow 2003b). The ability to persist through allochthonous food resources, in turn, might allow dispersal far beyond the limits of planktonic larval dispersal, as rafting is not limited by the duration of larval development (Thiel \& Gutow 2005a).

Acknowledgements. We thank R. Harvey for useful comments on the manuscript.

\section{LITERATURE CITED}

Aliani S, Molcard A (2003) Hitch-hiking on floating marine debris: macrobenthic species in the Western Mediterranean Sea. Hydrobiologia 503:59-67 
Anger K, Dawirs R (1981) Influence of starvation on the larval development of Hyas araneus (Decapoda, Majidae). Helgol Wiss Meeresunters 34:287-311

Bell G (1984) Measuring the cost of reproduction. I. The correlation structure of the life table of a planktonic rotifer. Evolution 38:300-313

Blaxter JH, Hempel G (1963) The influence of egg size on herring larvae (Clupea harengus L.). J Cons Perm Int Explor Mer 28:211-240

Butler JN, Stoner AW (1984) Pelagic Sargassum: has its biomass changed in the last 50 years? Deep-Sea Res 31: 1259-1264

Calow P, Sibly RM (1983) Physiological trade-offs and the evolution of life cycles. Sci Prog 68:177-188

Caswell H (2001) Matrix population models, 2nd edn. Sinauer Associates, Sunderland, MA

Clark A (1984) Lipid composition of two species of Serolis (Crustacea, Isopoda) from Antarctica. Br Antarct Surv Bull 64:37-53

Dooley JK (1972) Fishes associated with the pelagic Sargassum complex, with a discussion of the Sargassum community. Contrib Mar Sci 16:1-32

Dzikowski R, Hulata G, Harpaz S, Karplus I (2004) Inducible reproductive plasticity of the guppy Poecilia reticulata in response to predation cues. J Exp Zool 301A:776-782

Edgar GJ (1987) Dispersal of faunal and floral propagules associated with drifting Macrocystis pyrifera plants. Mar Biol 95: $599-610$

Franke HD, Janke M (1998) Mechanisms and consequences of intra- and interspecific interference competition in Idotea baltica (Pallas) and Idotea emarginata (Fabricius) (Crustacea: Isopoda): a laboratory study of possible proximate causes of habitat segregation. J Exp Mar Biol Ecol 227: 1-21

Furness RW, Todd CM (1984) Diets and feeding of fulmars Fulmaris glacialis during the breeding season: a comparison between St Kilda and Shetland colonies. Ibis 126:379-387

Gislason A, Astthorsson OS, Petursdottir H, Gudfinnsson H, Bodvarsdottir AR (2000) Life cycle of Calanus finmarchicus south of Iceland in relation to hydrography and chlorophyll a. ICES J Mar Sci 57:1619-1627

Gutow L (2003a) Competition, habitat segregation and metapopulation effects: perspectives for Idotea metallica (Crustacea, Isopoda) in the North Sea, PhD thesis, Free University Berlin

Gutow L (2003b) Local population persistence as a pre-condition for large-scale dispersal of Idotea metallica (Crustacea, Isopoda) on drifting habitat patches. Hydrobiologia 503: $45-48$

Gutow L, Strahl J, Wiencke C, Franke HD, Saborowski R (2006) Behavioural and metabolic adaptations of marine isopods to the rafting life style. Mar Biol 149:821-828

Gyllstroem M, Hansson LA (2004) Dormancy in freshwater zooplankton: induction, termination and the importance of benthic-pelagic coupling. Aquat Sci 66:274-295

Hagen W, Auel H (2001) Seasonal adaptations and the role of lipids in oceanic zoooplankton. Zoology 104:313-326

Hervant F, Renault D (2002) Long-term fasting and realimentation in hypogean and epigean isopods: a proposed adaptive strategy for groundwater organisms. J Exp Biol 205: 2079-2087

Hughes AD, Catarino AI, Kelly MS, Barnes DKA, Black KD (2005) Gonad fatty acids and trophic interactions of the echinoid Psammechinus miliaris. Mar Ecol Prog Ser 305: 101-111

Kirk KL (1997) Life-history responses to variable environments: starvation and reproduction in planktonic rotifers. Ecology 78:434-441
Kirkman H, Kendrick GA (1997) Ecological significance and commercial harvesting of drifting and beach cast macroalgae and seagrasses in Australia: a review. J Appl Phycol 9:311-326

Korczynski RE (1989) Biochemical composition of the isopod Mesidotea entomon (Linnaeus) from the western Arctic. Polar Biol 9:391-395

Lee RF, Hagen W, Kattner G (2006) Lipid storage in marine zooplankton. Mar Ecol Prog Ser 307:273-306

Levin L, Caswell H, Bridges T, DiBacco C, Cabrera D, Plaia G (1996) Demographic responses of estuarine polychaetes to pollutants: life table response experiments. Ecol Appl 6: $1295-1313$

Longhurst A, Sathyendranath S, Platt T, Caverhill C (1995) An estimate of global primary production in the ocean from satellite radiometer data. J Plankton Res 17:1245-1271

Melzner F, Forsythe JW, Lee PG, Wood JB, Piatkowski U (2005) Estimating recent growth in the cuttlefish Sepia officinalis: are nucleic acid-based indicators for growth and condition the method of choice? J Exp Mar Biol Ecol 317: $37-51$

Merriman JL, Kirk KL (2000) Temporal patterns of resource limitation in natural populations of rotifers. Ecology 81: 141-149

Naylor E (1955) The diet and feeding mechanism of Idotea. J Mar Biol Assoc UK 34:347-355

Niermann U (1986) Distribution of Sargassum natans and some of its epibionts in the Sargasso Sea. Helgol Meeresunters 40:343-353

Paschke KA, Gebauer P, Buchholz F, Anger K (2005) Seasonal variation in starvation resistance of early larval North Sea shrimp Crangon crangon (Decapoda: Crangonidae). Mar Ecol Prog Ser 279:183-191

Pianka ER (1981) Resource acquisition and allocation among animals. In: Townsend CR, Calow P (eds) Physiological ecology: an evolutionary approach to resource use. Blackwell Scientific Publications, Oxford, p 300-314

Prevedelli D, Simonini R (2001) Effects of diet and laboratory rearing on demography of Dinophilus gyrociliatus (Polychaeta: Dinophilidae). Mar Biol 139:929-935

Rochet MJ (2000) May life history traits be used as indices of population viability? J Sea Res 44:145-157

Saborowski R, Buchholz F (1996) Annual changes in the nutritive state of North Sea dab. J Fish Biol 49:173-194

Sano M, Omori M, Taniguchi K (2003) Predator-prey systems of drifting seaweed communities off the Tohoku coast, northern Japan, as determined by feeding habit analysis of phytal animals. Fish Sci 69:260-268

Shaffer JA, Doty DC, Buckley RM, West JE (1995) Crustacean community composition and trophic use of the drift vegetation habitat by juvenile splitnose rockfish Sebastes diploproa. Mar Ecol Prog Ser 123:13-21

Sibly RM, Calow P (1986) Physiological ecology of animals - an evolutionary approach. Blackwell Scientific Publications, Oxford

Stearns SC (1992) The evolution of life histories. Oxford University Press, New York

Steele JH (1976) Patchiness. In: Cushing DH, Walsh JJ (eds) The ecology of the seas. Blackwell Scientific Publications, London, p 98-115

Stelzer CP (2001) Resource limitation and reproductive effort in a planktonic rotifer. Ecology 82:2521-2533

Tessier AJ, Goulden CE (1982) Estimating food limitation in cladoceran populations. Limnol Oceanogr 27:707-717

Thiel M, Gutow L (2005a) The ecology of rafting in the marine environment. I. The floating substrata. Oceanogr Mar Biol 42:181-263 
Thiel M, Gutow L (2005b) The ecology of rafting in the marine environment. II. The rafting organisms and community. Oceanogr Mar Biol 43:279-418

Tilman D (1982) Resource competition and community structure. Princeton University Press, Princeton, NJ

Tollrian R, Dodson SI (1999) Inducible defences in Cladocera: constraints, costs, and multipredator environments. In: Tollrian R, Harvell CD (eds) The ecology and evolution of inducible defences. Princeton University Press, Princeton, NJ, p 177-202

Tuomi J, Jormalainen V, Ilvessalo H (1988) Does the aquatic isopod Idotea baltica minimize the survival cost of reproduction? Oikos 52:245-249

Editorial responsibility: Otto Kinne (Editor-in-Chief), Oldendorf/Luhe, Germany
Turner JP, Rooker JR (2006) Fatty acid composition of flora and fauna associated with Sargassum mats in the Gulf of Mexico. Mar Biol 149:1025-1036

Vandendriessche S, Vincx M, Degraer S (2006) Floating seaweed in the neustonic environment: a case study from Belgian coastal waters. J Sea Res 55:103-112

Wong CS, Green DR, Cretney WJ (1974) Quantitative tar and plastic waste distributions in the Pacific Ocean. Nature 247:30-32

Zöllner N, Kirsch K (1962) Über die quantitative Bestimmung von Lipoiden (Mikromethode) mittels der vielen natürlichen Lipoiden (allen bekannten Plasmalipoiden) gemeinsamen Sulphophosphovanillin-Reaktion. Z Gesamten Exp Med 135:545-561

Submitted: October 10, 2006; Accepted: February 1, 2007

Proofs received from author(s): August 3, 2007 